\title{
THE ROLES OF PLANT HORMONES IN STYLE AND STIGMA GROWTH IN GAILLARDIA GRANDIFLORA (ASTERACEAE) ${ }^{1}$
}

\author{
Ross E. KONING ${ }^{2}$ \\ Department of Botany, University of Michigan, Ann Arbor, Michigan 48109
}

\begin{abstract}
A B S T R A C T
Style and stigma elongation and stigma unfolding, and the roles of plant hormones in these processes in Gaillardia grandiflora Van Houtte were investigated. Style and stigma elongation in vivo began just after anthesis, and style elongation was accompanied by epidermal cell elongation (greatest near the stigma) and a fresh weight increase, but not by cell division or a dry weight increase. The stigma unfolded after the style and stigma elongated. Style-stigma units excised from young disc flowers of this composite were measured as they responded to plant growth regulators applied singly, as well as in sequential and simultaneous combinations, in vitro. Style elongation was promoted by auxin, was inhibited by gibberellins and ethylene, and was unaffected by other growth regulators. Stigma elongation followed a similar pattern of response. Endogenous auxin levels and ethylene production showed parallel variation and endogenous gibberellin levels showed inverse variation with style and stigma elongation. Stigma unfolding was more sensitive to auxin applications and was promoted by applied ethylene. Ethylene production showed parallel variation and endogenous auxin levels showed inverse variation with stigma unfolding. AVG and $\mathrm{Co}^{2+}$ applications decreased auxin-induced style elongation and fusicoccin promoted all of the growth responses of style-stigma units in vitro. A gibberellin-auxin-ethylene-acid growth interaction mode of control is proposed for these three growth processes.
\end{abstract}

THE FLOWERING PROCESS is composed of five sequential phases: flower induction, flower primordia differentiation, flower opening, anthesis and pollination, and flower senescence. Flower opening is the least-studied of these phases, but is composed of several elongation phenomena including corolla, filament, style and stigma elongation, and stigma unfolding. In the disc flower of the Asteraceae, the corolla is greatly reduced and does not elongate rapidly compared to the corolla of the ray flower. Filament elongation has been previously described in Gaillardia disc flowers (Koning, 1983).

The roles of plant hormones in style and stigma elongation have been partially demonstrated for several genera. In the most complete studies of this involvement, cytokinins (deJong and Bruinsma, 1974; Berghoef and Bruinsma, 1979) and gibberellins (Murakami,

Received for publication 23 July 1982, accepted 31 March 1983.

This work is part of a doctoral thesis submitted to the Rackham School of Graduate Studies, University of Michigan, Ann Arbor. The author is greatly indebted to Dr. Peter B. Kaufman (University of Michigan, Ann Arbor) for help with the manuscript and for equipment supplied through his National Aeronautics and Space Administration Grant NAGW-34. Dr. Jan Zeevaart (Michigan State University, East Lansing) provided valuable advice for the gibberellin analyses.

${ }^{2}$ Present address: Department of Biological SciencesBotany, Rutgers University, P.O. Box 1059, Piscataway, NJ 08854.
1973; Peterson, 1974) seem to be important, but the other hormones (auxins, ethylene, and abscisic acid) may also be implicated. Moreover, the plant hormones may interact with each other in producing the developmental responses, but multiple hormone relationships have not been thoroughly investigated. Environmental factors, such as nitrate levels, may also play an important role (Peterson, 1973; Berghoef and Bruinsma, 1979).

In the present work, the parameters of normal growth in the style-stigma unit, and the roles of plant hormones in the elongation of the style and stigma and in the unfolding of the stigma of the Gaillardia disc flower were examined. The sterile ray flowers of Gaillardia have only vestigial female parts and were therefore omitted from this study. The roles of plant hormones were examined both from study of the effects of growth regulator applications and measurement of endogenous hormone levels during development.

MATERIALS AND METHODS-Plant cultureGaillardia grandiflora Van Houtte cv 'Goblin' seeds were obtained from George W. Park Seed Co., Greenwood, South Carolina. Seedlings were grown to a stage with eight leaves under greenhouse conditions, and were transplanted to a field plot of sandy loam at the Matthaei Botanical Garden, Ann Arbor, Michigan. The plants flowered under long-day conditions of summer. 
Length and angle measurements - The stylestigma units (Fig. 1) were excised with fine forceps and a razor blade. The lengths of the styles and stigmas were measured to within 0.1 $\mathrm{mm}$ using a Finescale Comparator (Finescale Tools, Orange, California) which was fitted with a \#122 reticle. The angle between the stigma branches was measured to within $5^{\circ}$ using the \#123 reticle.

Cell length and cell number determinations-Wet mounts of styles were made, and the length of each epidermal cell of a longitudinal column of cells was measured with an Olympus Model EH microscope fitted with a calibrated optical micrometer. The cells in several columns were measured separately and compared as described by Greyson and Tepfer (1966). The mean cell length was compared for the styles at the five stages of flower opening (Fig. 1). To determine the uniformity of elongation, the length of cells was plotted as a function of position along the length of the style. The number of epidermal cells in each column was also counted to show the contribution of cell division to style elongation.

Fresh and dry weight determinationsGroups of style-stigma units from 25 flowers of each developmental stage were weighed on a Sartorius Model 2603 analytical balance before and after overnight oven drying at $80 \mathrm{C}$.

In vitro style-stigma growth-Style-stigma units were excised from 15 Stage II disc flowers and were placed in each $10-\mathrm{cm}$ petri dish containing a microslide, a disc of 9-cm diameter filter paper, and $6 \mathrm{ml}$ of a test solution. All test solutions contained $0.05 \mathrm{M}$ sucrose as a substrate for growth. The dishes were incubated in the dark at $30 \mathrm{C}$ in a Thelco Model 2 incubator. The style-stigma units were measured as described previously after $1,8,20,32,44$, and $56 \mathrm{hr}$ in vitro. The mean style and stigma lengths and mean stigma angle were calculated for each treatment.

Test solutions-AbA, $\mathrm{BA}, \mathrm{CCC}, \mathrm{CoCl}_{2}$, IAA, IPA, PCIB, TIBA, and $Z^{3}$ were obtained from Sigma Chemical Co., St. Louis, Missouri. AMO 1618 was obtained from Polysciences, Inc.,

\footnotetext{
${ }^{3}$ Abbreviations: AMO 1618: 4-hydroxy-5-isopropyl-2methylphenyl trimethyl ammonium chloride-1-piperidine carboxylate; AVG: L-2-amino-4-(2-aminoethoxy)-trans3-butenoic acid hydrochloride (or aminoethoxyvinylglycine); BS: brassinolide; CCC: 2-chloroethyltrimethyl ammonium chloride; $\mathrm{FC}$ : fusicoccin; $\mathrm{GA}_{4+7}$ : gibberellin $\mathrm{A}_{4}$ and $A_{7}$ mixture; IPA: isopentenyl adenine; PCIB: 4-chlorophenoxyisobutyric acid; TIBA: 2,3,5-triiodobenzoic acid; Z: zeatin.
}

Warrington, Pennsylvania. AVG was a gift from Maag Agrochemicals, Vero Beach, Florida. BS was a gift from Dr. W. Meudt, Beltsville, Maryland, to P. B. Kaufman. Fusicoccin was a gift from Montedison S.P.A., Milano, Italy. $\mathrm{GA}_{3}$ and $\mathrm{GA}_{4+7}$ were a gift from Imperial Chemical Industries Ltd., England, to P. B. Kaufman. Serial dilutions of $1 \mathrm{mM}$ stock solutions of these compounds were used as test solutions. Ethylene (1,000 nl/l) was obtained from Applied Sciences, State College, Pennsylvania, and was applied to the style-stigma units in rubber-sealed petri dishes by using a syringe for gas introduction. The atmosphere was changed at 2-hr intervals in an exhaust hood.

Auxin analyses - The amount of endogenous auxin was determined for $10 \mathrm{~g}$ of disc flowers at each stage of flower opening by using the double-standard isotope dilution assay designed by Cohen and Schulze (1981) as described previously (Koning, 1983). This method uses solvent partitioning, Sephadex A-25 column filtration, and high performance liquid chromatography (HPLC) for purification of auxin extracts. The analyses of purified auxins (with double internal standards) are made by gas chromatography with a nitrogen-phosphorus detector and scintillation counting.

Ethylene analyses - The amount of ethylene production was determined by gas chromatography for disc flowers at each developmental stage of flower opening as described previously (Koning, 1983).

Gibberellin analyses-The amount of endogenous gibberellin activity was estimated for disc flowers at each stage of flower opening by using the extraction and purification procedures of Jones, Metzger and Zeevaart (1980) and the 'Tan-ginbozu' dwarf rice bioassay developed by Murakami (1968). A weighed sample (approx. $10 \mathrm{~g}$ ) of flowers was ground for 2 min with a Waring blender and extracted overnight in $100 \mathrm{ml}$ of $80 \%(\mathrm{v} / \mathrm{v})$ aqueous methanol. The extract was filtered through Whatman \#1 filter paper, and the residue was washed with $100 \%$ methanol. The methanolic filtrates were combined and evaporated to the aqueous volume in a rotary evaporator. The aqueous extract was adjusted to $\mathrm{pH} 3$ with $1 \mathrm{~N} \mathrm{H}_{3} \mathrm{PO}_{4}$ and loaded onto a charcoal : celite $(2 \mathrm{~g}: 4 \mathrm{~g})$ column. The gibberellins were eluted with 250 $\mathrm{ml}$ of $80 \%(\mathrm{v} / \mathrm{v})$ aqueous acetone. The eluate was reduced to the aqueous volume in the rotary evaporator, adjusted to $\mathrm{pH} 2.5$, and partitioned against five half-volumes of ethyl acetate. The organic phases were pooled, reduced to their water content, and brought to $4 \mathrm{ml}$ 


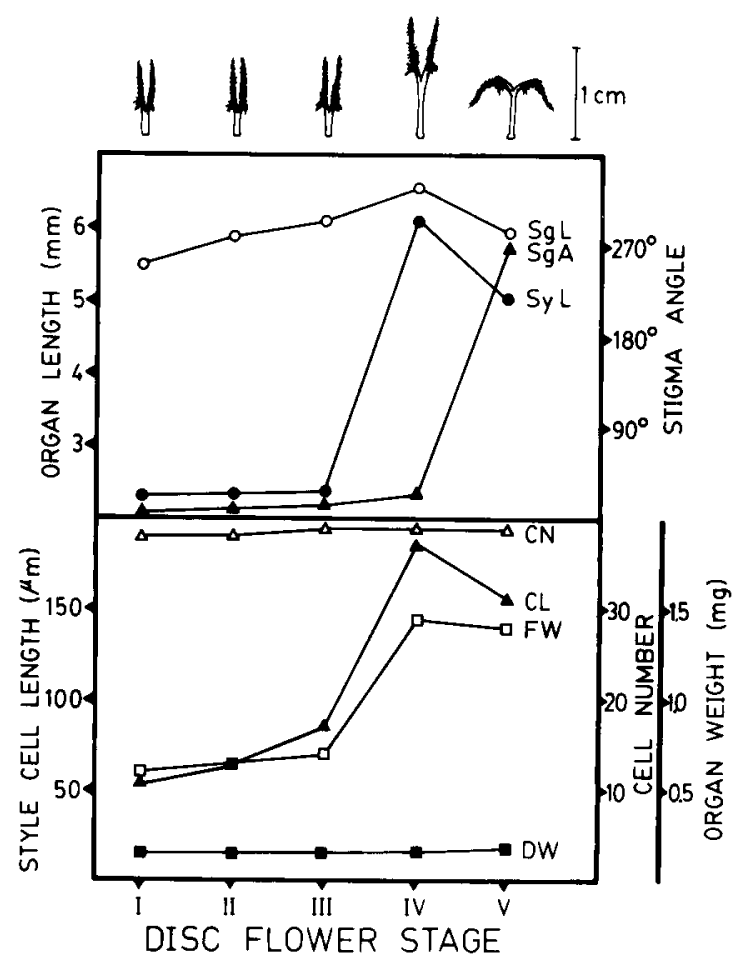

Fig. 1. Parameters of style and stigma growth. The mean stigma $(O)$ and style $(\Theta)$ length and stigma $(\Delta)$ angle changes during the five stages of disc flower opening in Gaillardia are compared with changes in epidermal cell length ( $\Delta$ ), epidermal cell number $(\Delta)$, fresh weight $(\square)$, and dry weight $(\square)$ of the style-stigma unit.

with $100 \%$ spectrograde methanol. Two $\mathrm{ml}$ of the crude extract were loaded onto a $25 \times 0.46$ $\mathrm{cm}$ Whatman Partisil 10 ODS-3 $\mathrm{C}_{18}$ reversephase HPLC column and eluted sequentially with $25 \mathrm{ml}$ of $5 \%, 20 \mathrm{ml}$ of $30 \%, 15 \mathrm{ml}$ of $70 \%$, and $15 \mathrm{ml}$ of $100 \%(\mathrm{v} / \mathrm{v})$ aqueous spectrograde methanol. The elution rate was adjusted to 2 $\mathrm{ml} / \mathrm{min}$ with a Milton-Roy HPLC pump (Anspec, Ann Arbor, Michigan). Fractions were collected at 1.5-min intervals, were taken to dryness, and dissolved in $100 \mu 1$ of absolute spectrograde methanol. Drops $(1 \mu \mathrm{l})$ of these purified fractions were applied to 'Tan-ginbozu' dwarf rice seedlings (The seeds were a gift from R. P. Pharis, Calgary, Canada). The gibberellin activity was estimated against a calibration curve of $\mathrm{GA}_{3}$. Indicated values above $10^{-7} \mathrm{M} \mathrm{GA}_{3}$-equivalent were summed for the fractions of each extract. The gibberellin content was calculated and expressed as $\mathrm{ng} \mathrm{GA}_{3}$ equivalent per gram fresh weight for the extracts of each stage.

RESULTS AND DISCUSSION-Style and stigma growth in vivo-The development of disc flow-

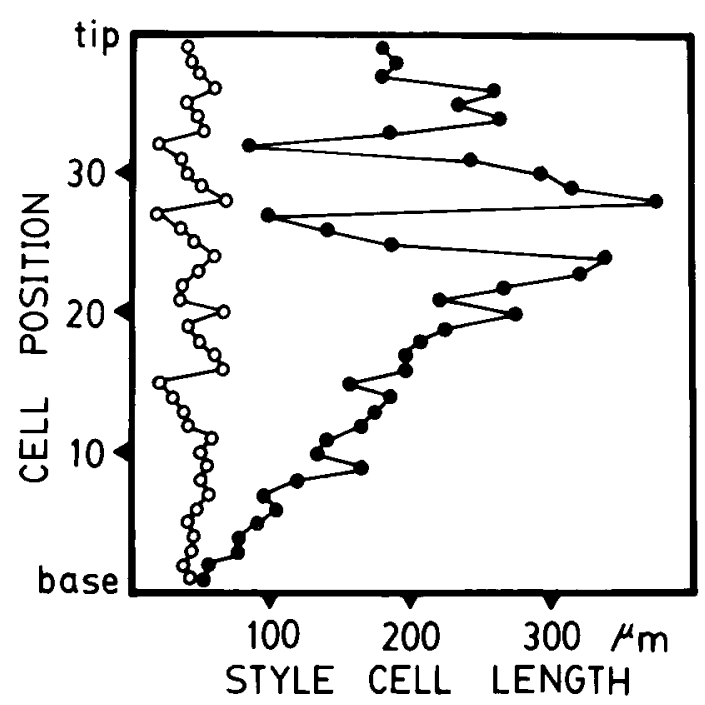

Fig. 2. Style epidermal cell length as a function of position in a column of cells, extending from the base of the style to the tip near the stigma, both before $(O)$ and after (e) style elongation in Gaillardia.

ers has been divided into five easily distinguished stages which are present at one time in the inflorescence (Koning, 1983). The stylestigma unit does not grow significantly during the first three stages (Fig. 1). The pollen is shed at Stage III in late morning and falls upon the stigma hairs. In the afternoon of the day of anthesis, the style and stigma elongate, and the stigma is pushed through the anther tube. Like a bottle brush, the two hairy stigma branches effectively remove the pollen from the anther tube as they emerge from the top of the flower (Stage IV). During the day after anthesis, pollinators remove the pollen from the emerging stigma and the stigma branches begin to reflex away from each other. The receptive surface between the branches is exposed, and the flower is pollinated by Stage V.

Parameters of style and stigma growth-Style elongation has been described as a process involving both fresh and dry weight increases during cell enlargement in several genera outside the Asteraceae (Goldschmidt and Huberman, 1974; Alpi et al., 1976; Dattagupta and Datta, 1976; Nichols, 1976; Camprubi and Nichols, 1978, 1979; Arditti and Harrison, 1979; Berghoef and Bruinsma, 1979). Style elongation in Gaillardia was reflected in epidermal cell elongation (Fig. 1); the cells between the two vascular bundles and the epidermis of the style could not be measured in fresh mount preparations. The epidermal cells of the style began development as cubical cells 
and elongated rapidly during style elongation; there was no increase in cell width during elongation. Cell elongation was greater near the stigma than near the base of the style (Fig. 2). Very short cells at the base of the style may be part of its abscission zone. Since the number of epidermal cells in each longitudinal column of cells remained at about 39 through style elongation (Fig. 1), cell division did not play a significant role in this growth. The elongation of the style was accompanied by an increase in fresh weight.

The elongation of the hairy stigma branches could not be monitored at the cellular level during flower opening due to the complexity of the epidermal system. Stigma elongation takes place simultaneously with style elongation and is therefore accompanied by the same fresh weight change (Fig. 1).

Stigma unfolding is a process limited to the Asteraceae and a few other families, and this process has not been studied from a developmental point of view. The stigma of Gaillardia unfolded between Stages IV and V of disc flower development (Fig. 1); the angle between the branches at Stage IV and earlier stages was $0^{\circ}$ and increased to about $270^{\circ}$ by Stage $\mathrm{V}$. Between these stages, there was little change in either fresh or dry weight of the style-stigma units. Although the surface of the stigma in the receptive areas is smooth, and it is this region that must elongate to cause the reflexing, the opposite surface of each branch, which must elongate relatively less, has many heavily pigmented epidermal trichomes and would not allow the necessary comparison to show the cellular basis for the unfolding mechanism.

The role of auxin-auxin has been shown to have little or no effect upon female organ growth in some species (Sawhney and Greyson, 1973; deJong and Bruinsma, 1974; Peterson, 1974; Berghoef and Bruinsma, 1979) and to inhibit female development in Mirabilis (Murakami, 1975). In contrast, IAA promotes growth by fresh and dry weight increases in the female parts of Cymbidium (Arditti and Harrison, 1979). Obviously, flowers of different families may have different roles for the various plant hormones in flower development. In Gaillardia, style and stigma elongation and stigma unfolding were all promoted by applied auxin (Fig. 3). Style and stigma elongation began sooner and the maximum length attained by the styles was greater at $10^{-4} \mathrm{M}$ IAA than in the presence of sucrose alone. These responses to IAA are dose dependent (Fig. 4). Stigma unfolding was more sensitive to IAA than the elongation phenomena and showed a significant response at $10^{-6} \mathrm{M}$ IAA. Auxin transport

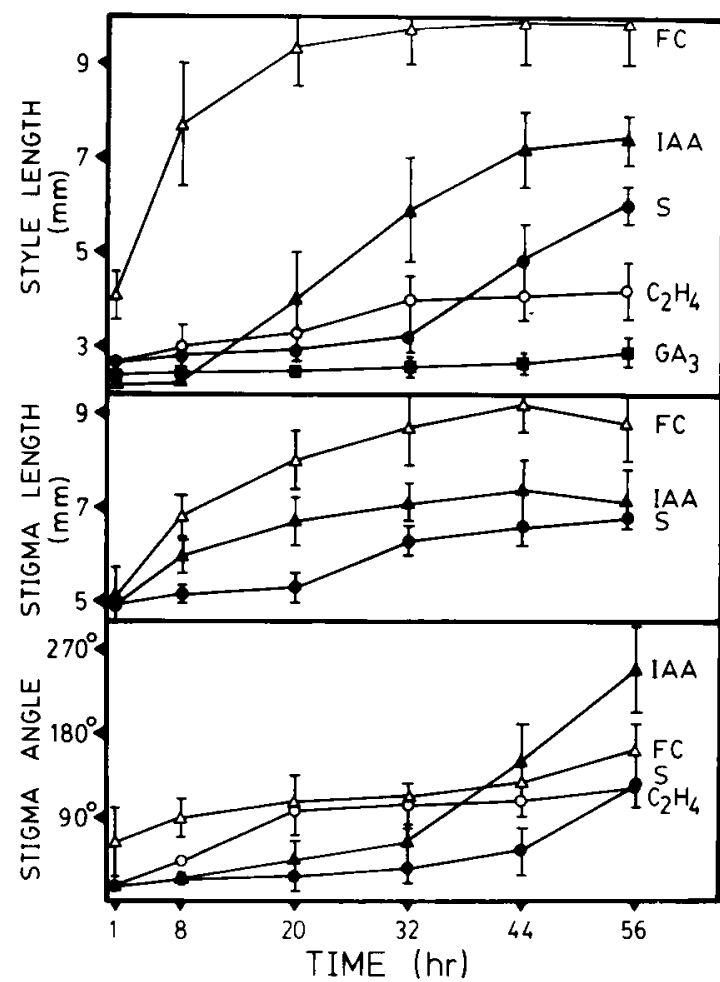

Fig. 3. The effects of growth regulators on the time course of style and stigma elongation and stigma unfolding in Gaillardia. The regulators: $10^{-4} \mathrm{M} \mathrm{FC}(\triangle), 10^{-4} \mathrm{M} \mathrm{IAA}$ $(\Delta), 10 \mathrm{nl} / 1$ ethylene $(O)$, and $10^{-5} \mathrm{M} \mathrm{GA}_{3}(\square)$, were applied as test solutions in vitro containing $0.05 \mathrm{M}$ sucrose as a substrate for growth and are compared with $0.05 \mathrm{M}$ sucrose alone $(\boldsymbol{O})$. The concentration of IAA used to show effects on stigma unfolding was $10^{-6} \mathrm{M}$. Vertical lines indicate \pm SD.

(TIBA) and action (PCIB) inhibitors had no effect on style and stigma growth when applied in vitro (Table 1). Endogenous hormone levels in Juglans show parallel variation with respect to female flower development (Sladký, 1972). In Gaillardia, the auxin level increased 25 -fold at Stage III to a level $\left(8.2 \times 10^{-4} \mathrm{M}\right)$ sufficient to induce growth in the style and stigma between Stages III and IV (Fig. 5). This high level declined by Stage IV to reduce the auxin inhibition of stigma unfolding between Stages IV and $\mathrm{V}$.

The role of ethylene-Hall and Forsyth (1967) have shown that auxin may promote flower development through an increase in ethylene production. Growth of female parts is promoted in Dianthus (Nichols, 1976; Camprubi and Nichols, 1978, 1979), is inhibited in Cleome (deJong and Bruinsma, 1974), and is unaffected in Begonia (Berghoef and Bruinsma, 1979) by applied ethylene. In Gaillardia, 
TABLE 1. Treatments having no significant dose effect in style and stigma elongation and stigma unfolding in Gaillardia

\begin{tabular}{|c|c|c|c|c|c|}
\hline \multirow[b]{2}{*}{ Regulator } & \multicolumn{5}{|c|}{ Concentration } \\
\hline & 0 & $10^{-7}$ & $10^{-6}$ & $10^{-5}$ & $10^{-4} \mathrm{M}$ \\
\hline \multicolumn{6}{|c|}{ MEAN STYLE LENGTH \pm SD AT $20 \mathrm{HR}$} \\
\hline PCIB & $2.6 \pm 0.3$ & $2.5 \pm 0.2$ & $2.5 \pm 0.2$ & $2.6 \pm 0.3$ & \multirow[t]{2}{*}{$2.9 \pm 1.0$} \\
\hline TIBA & $2.6 \pm 0.3$ & $2.6 \pm 0.3$ & $2.6 \pm 0.2$ & $2.7 \pm 0.2$ & \\
\hline $\mathrm{AMO}_{1618}$ & $2.5 \pm 0.2$ & $2.6 \pm 0.1$ & $2.5 \pm 0.1$ & $2.8 \pm 0.4$ & $3.0 \pm 0.7$ \\
\hline BA & $2.7 \pm 0.2$ & $3.0 \pm 0.6$ & $2.8 \pm 0.4$ & $3.5 \pm 1.0$ & $3.6 \pm 1.1$ \\
\hline IPA & $2.7 \pm 0.2$ & $2.6 \pm 0.2$ & $2.9 \pm 0.2$ & $3.0 \pm 0.3$ & $3.7 \pm 0.6$ \\
\hline $\mathrm{Z}$ & $2.7 \pm 0.2$ & $2.7 \pm 0.2$ & $2.8 \pm 0.2$ & $3.0 \pm 0.5$ & $3.6 \pm 0.9$ \\
\hline $\mathrm{AbA}$ & $2.4 \pm 0.1$ & $2.4 \pm 0.1$ & $2.4 \pm 0.1$ & $2.3 \pm 0.1$ & $2.4 \pm 0.2$ \\
\hline BS & $3.4 \pm 0.3$ & $3.5 \pm 0.5$ & $4.0 \pm 1.5$ & $3.9 \pm 1.0$ & \\
\hline \multicolumn{6}{|c|}{ MEAN STIGMA LENGTH \pm SD AT $20 \mathrm{HR}$} \\
\hline PCIB & $4.9 \pm 0.3$ & $4.9 \pm 0.3$ & $4.9 \pm 0.2$ & $5.1 \pm 0.4$ & \multirow[t]{2}{*}{$5.0 \pm 0.3$} \\
\hline TIBA & $4.9 \pm 0.2$ & $5.0 \pm 0.2$ & $5.0 \pm 0.3$ & $5.0 \pm 0.3$ & \\
\hline $\mathrm{GA}_{3}$ & $5.6 \pm 0.4$ & $5.6 \pm 0.4$ & $5.6 \pm 0.3$ & $5.4 \pm 0.4$ & $5.5 \pm 0.3$ \\
\hline $\mathrm{GA}_{4+7}$ & $5.6 \pm 0.4$ & $5.6 \pm 0.4$ & $5.5 \pm 0.2$ & $5.5 \pm 0.3$ & $5.5 \pm 0.4$ \\
\hline $\mathrm{AMO}_{1618}$ & $5.6 \pm 0.4$ & $5.6 \pm 0.4$ & $5.5 \pm 0.3$ & $5.7 \pm 0.4$ & $5.9 \pm 0.4$ \\
\hline $\mathrm{BA}$ & $5.1 \pm 0.2$ & $5.1 \pm 0.4$ & $5.0 \pm 0.4$ & $5.3 \pm 0.6$ & $5.4 \pm 0.4$ \\
\hline IPA & $5.1 \pm 0.2$ & $5.0 \pm 0.3$ & $5.1 \pm 0.3$ & $5.0 \pm 0.3$ & $5.4 \pm 0.5$ \\
\hline $\mathrm{Z}$ & $5.1 \pm 0.2$ & $5.0 \pm 0.4$ & $5.0 \pm 0.4$ & $5.1 \pm 0.3$ & $5.4 \pm 0.5$ \\
\hline $\mathrm{AbA}$ & $4.6 \pm 0.2$ & $4.7 \pm 0.2$ & $4.5 \pm 0.3$ & $4.7 \pm 0.2$ & $4.7 \pm 0.3$ \\
\hline BS & $5.7 \pm 0.6$ & $5.7 \pm 0.3$ & $5.8 \pm 0.4$ & $6.1 \pm 0.4$ & \\
\hline \multicolumn{6}{|c|}{ MEAN STIGMA ANGLE \pm SD AT $56 \mathrm{HR}$} \\
\hline PCIB & $130 \pm 70$ & $138 \pm 52$ & $104 \pm 59$ & $144 \pm 70$ & \multirow[t]{2}{*}{$155 \pm 80$} \\
\hline TIBA & $125 \pm 60$ & $151 \pm 77$ & $158 \pm 82$ & $127 \pm 49$ & \\
\hline $\mathrm{GA}_{3}$ & $142 \pm 50$ & $130 \pm 27$ & $141 \pm 20$ & $126 \pm 18$ & $232 \pm 73$ \\
\hline $\mathrm{GA}_{4+7}$ & $145 \pm 50$ & $181 \pm 49$ & $196 \pm 56$ & $201 \pm 60$ & $234 \pm 41$ \\
\hline $\mathrm{AMO}_{1618}$ & $142 \pm 50$ & $182 \pm 45$ & $157 \pm 44$ & $174 \pm 70$ & $191 \pm 47$ \\
\hline $\mathrm{BA}$ & $130 \pm 14$ & $128 \pm 10$ & $116 \pm 11$ & $142 \pm 20$ & $159 \pm 25$ \\
\hline IPA & $130 \pm 14$ & $135 \pm 22$ & $127 \pm 18$ & $146 \pm 31$ & $140 \pm 13$ \\
\hline $\mathrm{Z}$ & $130 \pm 14$ & $137 \pm 23$ & $138 \pm 24$ & $145 \pm 16$ & $150 \pm 27$ \\
\hline $\mathrm{AbA}$ & $100 \pm 18$ & $92 \pm 19$ & $108 \pm 19$ & $95 \pm 19$ & $110 \pm 10$ \\
\hline
\end{tabular}

applied ethylene inhibited style elongation, had no effect on stigma elongation, and promoted early ( $20 \mathrm{hr}$ ) stigma unfolding (Fig. 3 ). To date, little use of ethylene biosynthesis inhibitors (AVG and $\mathrm{Co}^{2+}$ ) has been made in the study of flower opening. In Gaillardia, AVG and $\mathrm{Co}^{2+}$ interfered with auxin-promoted growth of the style and greatly reduced the stigma unfolding response which is very sensitive to auxin application (Table 2). Parallel variation of ethylene production and female flower organ development has been demonstrated in several non-Asteraceae species (Hall and Forsyth, 1967; Arditti, Hogan and Chadwick, 1973; Lipe and Morgan, 1973; Blumenfeld, 1975; Nichols, 1977; Stead and Moore, 1979; Veen, 1979). In Gaillardia, ethylene production increased 3-fold during disc flower opening, and reached its maximum at Stage $V$ during and after stigma unfolding (Fig. 5).

The role of brassinolide - Brassinolide, a plant steroid hormone isolated from Brassica pollen
(Grove et al., 1979), and recently characterized and synthesized (Thompson et al., 1979), enhances many auxin-promoted growth responses (Yopp et al., 1979). In Gaillardia, style and stigma elongation were unaffected by brassinolide (Table 1), but stigma unfolding was inhibited by this hormone (Fig. 4). The brassinolide may enhance the endogenous auxin activity so significantly that an inhibitive level of activity is produced, or brassinolide has properties other than its synergism with auxin, that inhibit stigma unfolding. The observation that the stigma does not unfold until all of the Gaillardia pollen is removed by pollinators supports the idea that brassinolide, or a similar substance, is present with auxin in Gaillardia pollen. Lacking proper collection techniques for the many kilograms of pollen necessary to analyze the presence of brassinolide, such studies are planned for the future.

The role of acid growth-Another aspect of most auxin responses is the involvement of proton efflux from the cells. Fusicoccin, a fun- 


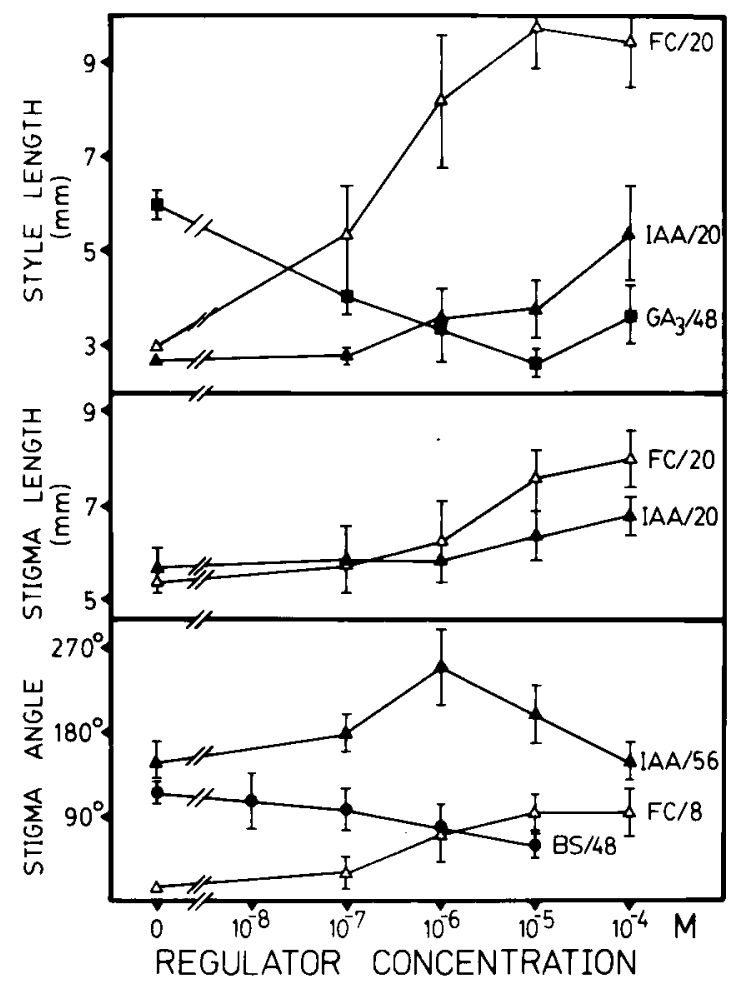

Fig. 4. Dose responses for FC ( $\triangle)$, IAA $(\Delta), G A_{3}(\square)$, and BS $(\bullet)$ in style and stigma elongation and stigma unfolding in Gaillardia. The lengths and angles are shown after times (in hr) in vitro appropriate to show the effects of the regulator: FC and IAA at $20 \mathrm{hr}$ and $\mathrm{GA}_{3}$ at $48 \mathrm{hr}$ for style and stigma elongation; FC at $8, \mathrm{BS}$ at 48 , and IAA at $56 \mathrm{hr}$ for stigma unfolding. Vertical lines indicate $\pm \mathrm{SD}$.

gal metabolite, also stimulates the proton pump and promotes rapid growth in many non-floral acid-responsive systems (Marré, 1979). In Gaillardia, FC stimulated filament growth (Koning, 1983), and style and stigma elongation and stigma unfolding (Fig. 3, 4). This compound was even more effective than IAA in promoting female organ growth; $10^{-4} \mathrm{M}$ FC treated style-stigma units showed measureable growth between the time the first unit was placed in the dish and the time that the initial measurements were made at $1 \mathrm{hr}$ (Fig. 3). FC also increased the final length of both style and stigma, but had no effect on the final stigma angle after an initial promotion of stigma unfolding. FC-promoted growth was less sensitive to ethylene biosynthesis inhibitors than IAA-promoted growth (Table 2). Some type of acid growth is probably involved in these developmental phenomena in Gaillardia, but may be restricted to the initiation of the growth responses.
TABLE 2. The interactions between acid-growth promoting treatments (IAA, FC, pH 5 buffer) and ethylene biosynthesis inhibitors $\left(A V G, C^{2+}\right)$ in style elongation and stigma unfolding in Gaillardia

\begin{tabular}{lccc}
\hline \multirow{2}{*}{$\begin{array}{c}\text { Test solution } \\
\text { component }\end{array}$} & \multicolumn{3}{c}{ Additional test solution component } \\
\cline { 2 - 4 } None & AVG & Co $^{2+}$ \\
\hline MEAN STYLE LENGTH \pm SD AT & $32 \mathrm{HR}$ & \\
None & $3.9 \pm 0.5$ & $3.7 \pm 0.4$ & $3.2 \pm 0.5$ \\
IAA & $7.3 \pm 1.2$ & $5.1 \pm 1.4$ & $5.1 \pm 0.9$ \\
FC & $8.7 \pm 1.6$ & $8.9 \pm 1.4$ & $7.7 \pm 1.1$ \\
pH 5 buffer & $4.6 \pm 0.8$ & - & - \\
MEAN STIGMA ANGLE \pm SD AT & $56 \mathrm{HR}$ & \\
None & $214 \pm 58$ & $146 \pm 48$ & $105 \pm 20$ \\
IAA & $263 \pm 37$ & $121 \pm 29$ & $97 \pm 34$ \\
FC & $159 \pm 27$ & $183 \pm 19$ & $138 \pm 10$ \\
pH 5 buffer & $152 \pm 29$ & - & - \\
\hline
\end{tabular}

The role of gibberellins-Female organ growth is promoted (Peterson, 1974; Murakami, 1975), is inhibited (deJong and Bruinsma, 1974), or is unaffected (Berghoef and Bruinsma, 1979) by gibberellins in different species. In Gaillardia, style elongation was inhibited by gibberellins (Fig. 3, 4). The maximum inhibition of style elongation was obtained at $10^{-5} \mathrm{M} \mathrm{GA}_{3}$; similar results were obtained with the less-polar $\mathrm{GA}_{4+7}$ mixture (Koning, 1981). Stigmas did not elongate significantly in response to the gibberellins (Table 1). In contrast, stigma unfolding was promoted by both gibberellins at $10^{-4} \mathrm{M}$ (Table 1). The gibberellin synthesis inhibitor, AMO 1618, inhibits female organ growth in Nigella (Peterson, 1974), but did not affect style or stigma elongation, or stigma unfolding in Gaillardia (Table 1). Parallel variation of native gibberellins and female organ development has been demonstrated directly (Peterson, 1974; Murakami, 1975) and indirectly (Einert, Staby and DeHertogh, 1972; Jeffcoat and Cockshull, 1972; Sladký, 1972; Murakami, 1973; Alpi et al., 1976; Ilahi, 1979; Zieslin, Madori and Halevy, 1979) in different species. The gibberellin levels increase near anthesis, just prior to rapid growth of the flower parts (especially the corolla), and then drop off suddenly in these species. By contrast, native gibberellin content varies inversely with flower development in other species (Wheeler, 1972; Leshem and Ophir, 1977; Dathe and Sembdner, 1980). This form of variation may be equally causative; the decreasing gibberellin concentration may represent the reduction of an inhibiting level of gibberellins in the flower, and the flowers open. In Gaillardia, the sum total gibberellin content in $\mathrm{GA}_{3}$-equivalents was at a higher level $(8 \times$ 


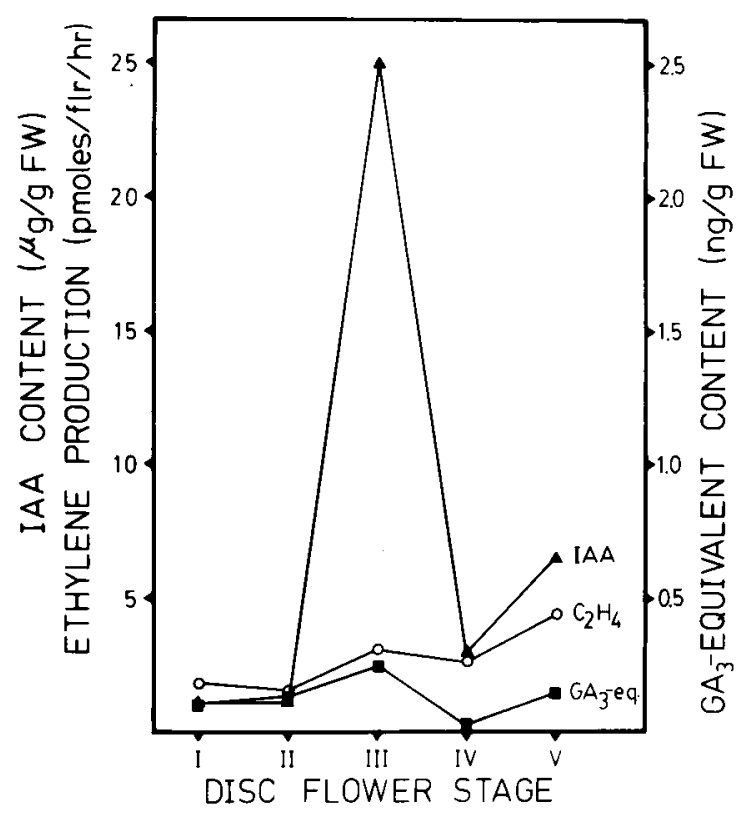

Fig. 5. Levels of endogenous IAA (A), GA $\mathrm{G}_{3}$-equivalents $(\square)$, and ethylene production $(O)$ during the five stages of flower opening in Gaillardia disc flowers.

$10^{-7} \mathrm{M}$ ) during Stages I-III when female organ growth was not observed, and dropped to $1 / 10$ of this level by Stage IV when female organ growth was observed (Fig. 5). The types of gibberellins also changed during style and stigma elongation (Fig. 6). In Stages I-III, morepolar gibberellins were present and their activity increased during these stages. These forms were replaced by less-polar forms at Stage III, and the $\mathrm{GA}_{3}$-equivalent activity decreased as the flowers continued to develop through Stage IV. Inhibitors present in fractions \#18-23 of all of the extracted stages may have been artifacts of extraction created by the disruption of the cell and tissue compartmentation. Alternatively, they may serve to mask the effects of the gibberellins during all of the stages in disc flower opening. Furthermore, the amount of gibberellins indicated here would be underestimates of gibberellins with lower activity or overestimates of gibberellins with higher activity than $\mathrm{GA}_{3}$ in the bioassay. Since the natural gibberellins of Gaillardia remain unidentified, we cannot possibly know whether the amount of gibberellin is accurately represented in the figures. In spite of these difficulties in measuring the many natural gibberellin isomers, the total activity level (in $\mathrm{GA}_{3}$-equivalents) allows comparisons between stages indicating functionally important (but

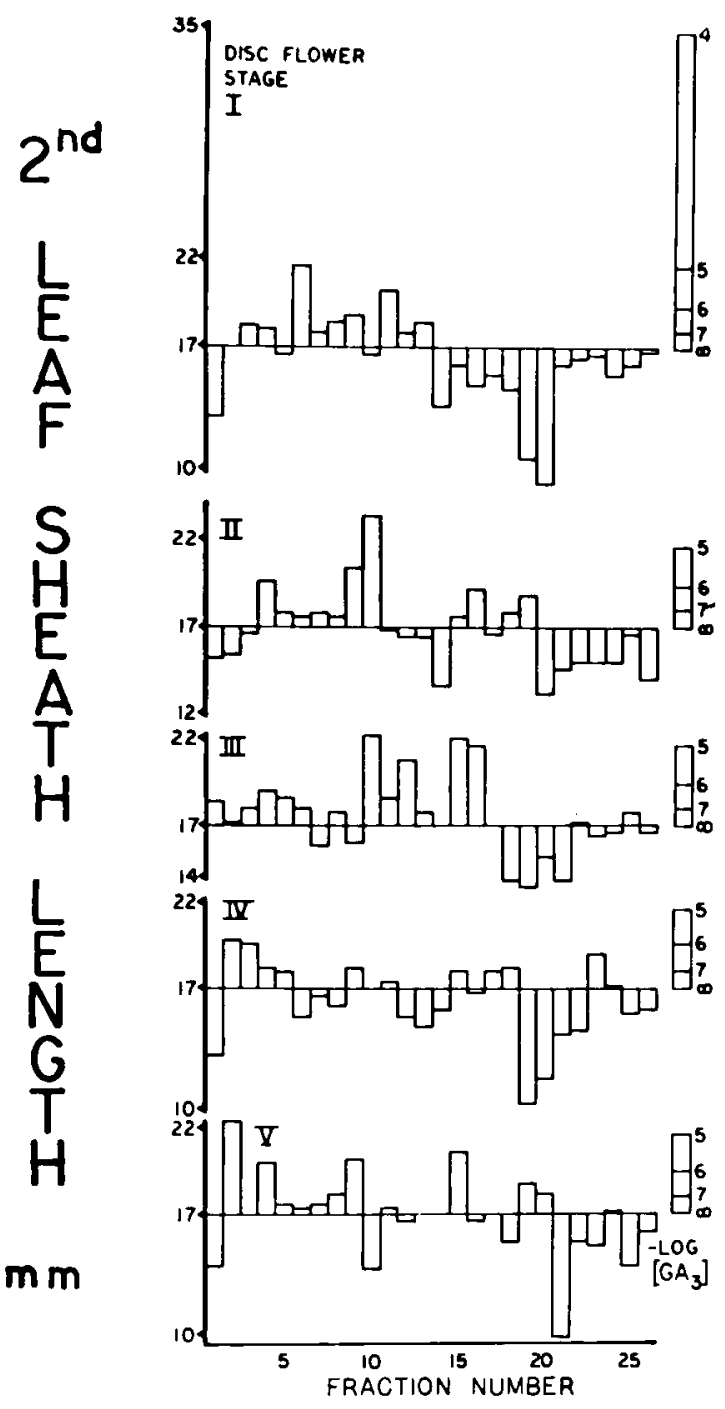

Fig. 6. The gibberellin content of HPLC-fractions of extracts of Gaillardia disc flowers as determined by the 'Tan-ginbozu' dwarf rice bioassay. More-polar gibberellins elute in the earlier fractions (\#1-13) and less-polar gibberellins elute in the later fractions (\#14-26) from the reverse-phase column.

biochemically obscured) changes in the gibberellins.

The roles of cytokinins-Cytokinins have been found to promote female organ growth in several species (Doazan and Cuellar, 1970; Hicks and Sussex, 1970; deJong and Bruinsma, 1974; Pool, 1975; Berghoef and Bruinsma, 1979), and parallel variation of natural cytokinins and female development has been demonstrated in Cucumis (Borkowska and Bor- 
TABLE 3. The effects of $10^{-5} \mathrm{M} G A_{3}$ and $10^{-4} \mathrm{M} I A A$, applied singly and in sequential and simultaneous combinations, upon style elongation in Gaillardia. After 7 $h r$, the style-stigma units were transferred from a dish containing the treatment in the numerator to one containing the treatment in the denominator. The style lengths shown were measured after $44 \mathrm{hr}$ in vitro to show the effects of $G A_{3}$

\begin{tabular}{lc}
\hline \hline $\begin{array}{c}\text { Hormone treatment } \\
(7 \mathrm{hr} / \text { balance })\end{array}$ & $\begin{array}{c}\text { Mean style } \\
\text { length } \pm \text { SD } \\
\text { at } 44 \mathrm{hr}\end{array}$ \\
\hline None/none & $6.2 \pm 0.7$ \\
$\mathrm{GA}_{3} / \mathrm{GA}_{3}$ & $3.3 \pm 0.4$ \\
$\mathrm{IAA} / \mathrm{IAA}$ & $7.3 \pm 1.1$ \\
$\mathrm{GA} / \mathrm{IAA}$ & $3.5 \pm 0.2$ \\
$\mathrm{IAA} / \mathrm{GA}{ }_{3}$ & $6.3 \pm 1.4$ \\
$\mathrm{IAA}+\mathrm{GA}_{3} / \mathrm{IAA}+\mathrm{GA}_{3}$ & $4.6 \pm 1.0$ \\
\hline
\end{tabular}

kowski, 1975). Applied synthetic (BA) and natural (IPA, Z) cytokinins had no effect upon female organ growth in Gaillardia (Table 1); it is doubtful that they play an important role.

The role of abscisic acid-Abscisic acid has been shown to have no effect on female development in Begonia (Berghoef and Bruinsma, 1979) and inhibits growth in Cleome (deJong and Bruinsma, 1974). In Gaillardia, $\mathrm{AbA}$ had no effect upon any of the growth processes (Table 1).

The role of hormone interactions-Interactions between hormones have not been examined in other studies of flower opening, but simultaneous and sequential applications of hormones (Koning, 1981) showed only one significant relationship. Sequential application of $\mathrm{GA}_{3}$ and IAA at maximum-response concentrations showed that $\mathrm{GA}_{3}$ inhibited IAA-induced style growth when applied before or along with IAA, but did not significantly affect growth when applied after IAA (Table 3). The model for GA-IAA interaction control (Chromiński and Kopcewicz, 1972) seems to represent reality in style elongation in Gaillardia.

The analyses of roles of individual hormones and their interactions lead to the idea that style and stigma development in Gaillardia is controlled by at least three hormones which interact to regulate the timing of growth. It would appear that style and stigma growth is inhibited in Stages I-III by the high level of gibberellins present in disc flowers. At Stage III, a huge increase of auxin triggers filament elongation which is insensitive to gibberellins (Koning, 1983). The gibberellin concentration declines rapidly in the flower and releases the inhibition of style elongation. The style and stigma elongate between Stages III and IV in response to the high auxin concentration. The auxin content then declines and ethylene production increases to promote stigma unfolding at Stage IV; brassinolide may also help delay unfolding by enhancing the auxin activity or by direct effect until pollen removal at Stage IV.

\section{LITERATURE CITED}

Alpi, A., N. Ceccarelli, F. Tognoni, and G. Gregorini. 1976. Gibberellin and inhibitor content during Iris bulb development. Physiol. Plant. 36: 362-367.

Arditti, J., AND C. R. Harrison. 1979. Postpollination phenomena in orchid flowers. VIII. Water and dry weight relations. Bot. Gaz. 140: 133-137.

-, N. M. Hogan, ANd A. V. Chadwick. 1973. Postpollination phenomena in orchid flowers. IV. Effects of ethylene. Amer. J. Bot. 60: 883-888.

Berghoef, J., AND J. Bruinsma. 1979. Flower development of Begonia franconis Liebm. II. Effects of nutrition and growth-regulating substances on the growth of flower buds in vitro. Z. Pflanzenphysiol. 93: 345-357.

Blumenfeld, A. 1975. Ethylene and the Annona flower. Plant Physiol. 55: 265-269.

BORKOWSKA, B., AND J. BORKOWSKI. 1975. Endogenous cytokinin-like compounds and growth inhibitors in pistillate and staminate cucumber flowers (Cucumis sativus L.). Bull. Acad. Pol. Sci. 23: 291-294.

CAmprubi, P., AND R. Nichol.s. 1978. Effects of ethylene on carnation flowers (Dianthus caryophyllus) cut at different stages of development. J. Hort. Sci. 53: 1722.

- AND - 1979. Ethylene-induced growth of petals and styles in the immature carnation inflorescence. J. Hort. Sci. 54: 225-228.

Chromiński, A., AND J. KopCEwicz. 1972. Auxins and gibberellins in 2-chloroethylphosphonic acid-induced femaleness of Cucurbita pepo L. Z. Pflanzenphysiol. 68: 184-189.

Cohen, J. D., ANd A. Schulze. 1981. Double standard isotope dilution assay. I. Quantitative assay of indole3-acetic acid. Anal. Biochem. 112: 249-257.

Dathe, W., and G. Sembdner. 1980. Endogenous plant hormones of the broad bean, Vicia faba L. II. Gibberellins and plant growth inhibitors in floral organs during their development. Biochem. Physiol. Pflanz. 175: 599-610.

Dattagupta, S., and P. C. Datta. 1976. Some aspects of androgynophore development in Cleome rutidosperma. Phytomorphology 26: 102-108.

DEJong, A. W., AND J. Bruinsma. 1974. Pistil development in Cleome flowers. III. Effects of growth-regulating substances on flower buds of Cleome iberidella Welw. ex Oliv. grown in vitro. Z. Pflanzenphysiol. 73 142-151.

Doazan, J. P., and V. Cuellar. 1970. Modification artificielle de l'expression du sexe dans le genre Vitis. Ann. Amélior. Plant. 20: 79-86.

Einert, A. E., G. L. Staby, and A. A. DeHertogh. 1972. Gibberellin-like activity from organs of Tulipa gesneriana. Can. J. Bot. 50: 909-914.

Goldschmidt, E. E., and M. Huberman. 1974. The coordination of organ growth in developing Citrus 
flowers: a possibility for sink-type regulation. J. Exp. Bot. 25: 534-541.

Greyson, R. I., AND S. S. TEPFER. 1966. An analysis of stamen filament growth of Nigella hispanica. Amer. J. Bot. 53: 485-490.

Grove, M. D., G. F. Spencer, W. K. Rohwedder, N. Mandaya, J. F. Worley, J. D. Warthen JR., G. L. Steffens, J. L. Flippen-Anderson, And J. C. CoOK JR. 1979. Brassinolide, a plant growth-promoting steroid isolated from Brassica napus pollen. Nature 281: 216-217.

Hall, I. V., AND F. R. Forsyth. 1967. Production of ethylene by flowers following pollination and treatments with water and auxin. Can. J. Bot. 45: 11631166.

Hicks, G. S., AND I. M. Sussex. 1970. Development in vitro of excised flower primordia of Nicotiana tabacum. Can. J. Bot. 48: 133-139.

ILAHI, I. 1979. Nature and balance of growth regulators in the reproductive organs of Ceratonia siliqua $\mathrm{L}$. Phyton 37: 29-34.

JefrCoAt, B., AND K. E. Cockshull. 1972. Changes in the levels of endogenous growth regulators during development of the flowers of Chrysanthemum morifolium. J. Exp. Bot. 23: 722-732.

Jones, M. G., J. D. Metzger, and J. A. D. ZeevaArr. 1980. Fractionation of gibberellins in plant extracts by reverse-phase high performance liquid chromatography. Plant Physiol. 65: 218-221.

Koning, R. E. 1981. Control of flower opening by plant hormones in Gaillardia grandiflora. Ph.D. thesis, University of Michigan, Ann Arbor.

- 1983. The roles of auxin, ethylene, and acid growth in filament elongation in Gaillardia grandiflora (Asteraceae). Amer. J. Bot. 70: 602-610.

LESHEM, Y., AND D. OPHIR. 1977. Differences in endogenous levels of gibberellin activity in male and female partners of two dioecious tree species. Ann. Bot. 41: 375-379.

Lipe, J. A., AND P. W. Morgan. 1973. Location of ethylene production in cotton flowers and dehiscing fruits. Planta 115: 93-96.

MARRÉ, E. 1979. Fusicoccin: a tool in plant physiology. Annu. Rev. Plant Physiol. 30: 273-312.

Murakami, Y. 1968. A new rice seedling test for gibberellins, 'microdrop method,' and its use for testing extracts of rice and morning glory. Bot. Mag. 81: 3343.

. 1973. The role of gibberellins in the growth of floral organs of Pharbitis nil. Plant Cell Physiol. 14: 91-102.
1975. The role of gibberellins in the growth of floral organs of Mirabilis jalapa. Plant Cell Physiol. 16: $337-345$

Nichols, R. 1976. Cell enlargement and sugar accumulation in the gynecium of the glasshouse carnation (Diant hus caryophyllus L.) induced by ethylene. Planta 130: 47-52.

- 1977. Sites of ethylene production in the pollinated and unpollinated senescing carnation (Dianthus caryophyllus) inflorescence. Planta 135: 155-159.

Peterson, C. M. 1973. Nutritional requirements for ovule formation in excised pistils of Nigella. Amer. J. Bot. 60: $381-386$.

1974. The effects of gibberellic acid and a growth retardant on ovule formation and growth of excised pistils of Nigella (Ranunculaceae). Amer. J. Bot. 61: 693-698.

Pool, R. M. 1975. Effect of cytokinin on in vitro development of 'Concord' flowers. Amer. J. Enol. Viticult. 26: 43-46.

Sawhney, V. K., and R. I. Greyson. 1973. Morphogenesis of the stamenless- 2 mutant in tomato. II. Modifications of the sex organs in the mutant and normal flowers by plant hormones. Can. J. Bot. 51: 24732479.

SLADKÝ, Z. 1972. The role of endogenous growth regulators in the differentiation processes of walnut ( $\mathrm{Ju}$ glans regia L.). Biol. Plant. 14: 273-278.

Stead, A. D., And K. G. Moore. 1979. Studies on flower longevity in Digitalis. Planta 146: 409-414.

Thompson, M. J., N. MANDAVA, J. L. FlipPEn-ANDERSON, J. F. Worley, S. R. DUtKY, W. E. Robbins, AND W. LusBY. 1979. Synthesis of brassinosteroids: new plant-growth-promoting steroids. J. Org. Chem. 44: 5002-5004.

VEEN, H. 1979. Effects of silver on ethylene synthesis and action in cut carnations. Planta 145: 467-470.

WHEELER, A. W. 1972. Changes in growth-substance contents during growth of wheat grains. Ann. Appl. Biol. 72: 327-334.

Yopp, J. H., G. C. Colclasure, and N. Mandava. 1979. Effects of brassin-complex on auxin and gibberellin mediated events in the morphogenesis of the etiolated bean hypocotyl. Physiol. Plant. 46: 247-254.

Zieslin, N., G. Madori, AND A. H. Halevy. 1979. Involvement of hormonal balance in the control of the 'bullhead' malformation in Baccara rose flowers. $\mathbf{J}$. Exp. Bot. 30: 15-25. 